\title{
Objective Limits of Peacebuilding Exercises: Professionals as a Bridge between Communities in Serbia and Kosovo* in the Practice of the Belgrade Fund for Political Excellence
}

Marko Savković ${ }^{1}$

\section{Abstract}

From 2012 on, BFPE, along with a number of other civil society organizations, used the space opened by first agreements on normalization of relations between Belgrade and Pristina, by supporting as concrete peacebuilding efforts expert symposiums, presentations of accomplishments of outstanding individuals and study visits. In doing so, the organization encountered several key challenges, some of which proved difficult to overcome. By reaching what we understand "objective limits of peacebuilding" it learned valuable lessons which may inform similar activities planned in the future.

Keywords: Serbia, Kosovo, BFPE, peacebuilding, normalization, human security

1 Marko Savković, PhD, Program Director of the Belgrade Fund for Political Excellence and the Belgrade Security Forum, Republic of Serbia, E-mail: msavkovic@bfpe.org 


\section{Objective Limits of Peacebuilding Exercises: Professionals as a Bridge between Communities in Serbia and Kosovo* in the Practice of the Belgrade Fund for Political Excellence}

\section{Introduction}

There is a persistent and pervasive point of view, mainstreamed in Serbia's public opinion, that Albanians and Serbs are incapable of building functional relationships because of, first, a difficult shared history, where the sides took turns in dominating each other; second, fundamentally opposed foreign policy interests, where one side is fighting for recognition(s) and the other has invested a tremendous amount of effort in revoking them; and third, the language barrier (a problem mostly between younger generations ${ }^{2}$ ) that makes communication and thus experience sharing slightly more difficult than it was the case with other nations in former Yugoslavia. Little is known of shared customs, cultural preferences and similarities (after all, we do inhabit the same "space"), other than in anecdotal form.

Following the unilateral declaration of independence (UDI) and Serbia's - at the time - protracted efforts to prevent it, the dynamics somewhat changed. The public in Kosovo*3 briefly moved its focus away from the aftermath of an interethnic conflict and peacebuilding to the context of state- and nation-building. Official Belgrade tried to find a formula to keep its European aspirations alive, following the mandate won by pro-European parties in 2008; accession to the European Union was soon conditioned upon the normalization of relations with Pristina. The "Brussels dialogue", as it came to be known, started in

2 Most Albanians in Kosovo under the age of 30 do not speak Serbian (Serbo-Croatian), the mandatory official language in former Yugoslavia. The same can be said for ethnic Serbs, who do not read or speak Albanian, despite the obvious benefits.

3 *This designation is without prejudice to positions on status, and is in line with UNSCR 1244/1999 and the ICJ Opinion on the Kosovo declaration of independence. 


\section{European Human}

Page I 76

earnest on 8-9 March 2011, following the International Court of Justice (ICJ)'s opinion of October 2010 (Janjić, 2015), the UN General Assembly's Resolution, and EU Council decision, first as a "technical" process led by highranking civil servants, and then, a "political" one as well, with prime ministers meeting. This dichotomy would continue - in the EU parlance, "technical dialogue" is led between Belgrade and Pristina, while the "political dialogue" is one that should result in a "comprehensive, legally binding agreement" on "normalization of relations" between Serbia and Kosovo*4. For Serbia, and to a lesser degree Kosovo*5, the two processes - normalization of mutual relations and European integration - have by March 2012 and yet another decision of the European Council become inseparable (Janjić, 2015).

This context of normalization, which came about gradually, followed the signing of the first technical ${ }^{6}$

4 This phrase was used for the first time in the European Commission's important communication A credible enlargement perspective for and an enhanced EU engagement with the Western Balkans, published in February 2018 (European Commission, 2018: $7,8,18)$.

5 We say "to a lesser degree" since Kosovo* faces another important hurdle: five EU members still do not recognize its UDI, making any consensus-based decision on its progress and eventual membership difficult. Also, as of 2019, its citizens (and those of Serbia who possess documents issued by Belgrade but have residency in Kosovo*) still need a visa to enter the EU; a deeply divisive issue, with many local intellectuals accusing Brussels (or, in this particular case, EU capitals - Den Haag and Paris) of "xenophobia"; and many experts from the region calling EU's lack of a common approach on the matter of the visa regime - shortsighted. 6 Over time, a somewhat unclear distinction was established between "technical" agreements and those stemming from the "political dialogue". Among technical agreements, we count those on the freedom of movement; a civil registry book; a cadastre; university degrees; customs stamps; integrated border/ boundary management (IBM); regional representation and cooperation; energy; telecommunications; vehicle insurance; the Mitrovica bridge; and another group called "principles governing normalisation" - integration of the judiciary; law enforcement; integration of civil protection corps; and the Association of Serb Municipalities. The original "political one" is the Brussels Agreement (The First Agreement on Principles Governing the Normalisation of Relations) of April 2013.

Issue 3 / 2019

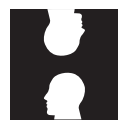




\section{European Human}

agreement, on the freedom of movement, back in 2011 . In this way, the first precondition, the ability to freely cross the border/boundary ${ }^{7}$ and visit places on the other side, was met. Despite occasional flare-ups, this particular regime has not been interrupted, and is seen as one of the process's greatest accomplishments. ${ }^{8}$ Within the two communities there was positive curiosity to break out of the vicious circle of conflict, but a concrete interest as well: 77 I Page regional cooperation was seen as one way to facilitate good neighbourly relations, understood as a prerequisite for membership in the EU. Also, with many regional networks established, it was understood that bilateral projects and activities make for a logical next step.

All this was in line with the idea of incremental, small, step-by-step progress: paraphrasing, "let trade kick in, and the rest will sort itself out" was one of the cornerstones of the EU's approach to the issue. ${ }^{9}$ In support came CEFTA (Central European Free Trade Agreement): in a little over a decade, Serbia's exports within the free trade area of Albania, Bosnia and Herzegovina, Montenegro, Moldova, North Macedonia and Kosovo ("Kosovo (UNMIK)" as the designation goes ${ }^{10}$ ) reached

7 While Pristina uses the term "border", Belgrade insists on "boundary" (the literal translation from Serbian would be "the administrative line").

8 This regime is in the best interest of both sides. While Serbia's citizens would be able to travel freely to their places of residence, Kosovo citizens would be able to reach EU and in particular Western European countries without difficulties. Not even the introduction of the $100 \%$ tariffs regime in November 2018 by Pristina affected it, as Belgrade restrained from retaliative measures. Findings from focus groups organized by the Kosovo-Serbia Policy Advocacy Group (KSPAG), a consortium of eight civil society organizations, support the claim of free movement of people as the single greatest achievement of the technical dialogue. These findings will be first presented to public and then published in January or February 2020. For more detailed information see next link: http://k-s-pag.org/.

9 This has not changed; see, for example, EU Commissioner Johannes Hahn's statement from 3 December 2018, one month following the introduction of the $100 \%$ tariffs (Hahn: I put forward free trade ideas before Kosovo* and Serbia, 2018).

10 For more detailed information see next link: http://cefta.int/ cefta-parties-2/. 


\section{European Human \\ Journal of Security}

$€ 3$ billion- against €800 million in imports - resulting in a significant trade surplus. Out of these exports, in 2017, close to 500 million $^{11}$ were destined for Kosovo (Vujadinović, 2018). Multinational companies, like CocaCola, Nestle or Phillip Morris, but also brands recognized throughout the region (Bambi and Štark confectioneries and Hemofarm pharmaceuticals), led the way. They were, however, followed by an increasing number of small and medium-sized enterprises (SMEs) that saw an opening, first as suppliers to Kosovo's burgeoning construction industry ${ }^{12}$, and then in other sectors as well. For instance, in Raška District with Kraljevo as its centre alone, there are approximately 500 SMEs and individuals that provide goods and services to Kosovo (Kosovo-Serbia Policy Advocacy Group Consortium (2019). Businesspeople were followed by artists - actors, writers - and then, civil society activists. Also, out of public view, the very first "track II diplomacy" ${ }^{13}$ events began to unfold, with MPs representing two societies meeting and discussing difficult issues for the very first time.

From the standpoint of what is considered a "working definition" of human security (Alkire, 2003: 2-3), Belgrade Fund for Political Excellence (BFPE)'s activities were organized with the awareness that "people and communities are affected by events beyond their control" (Ibid). These events, difficult to foresee, were acknowledged in our project applications not as "threats" but rather as "risks". The actors that we expected to

$11 € 471$ million to be exact (Srbija bi mogla da izgubi milione evra zbog mera Kosova, 2018).

12 Companies from Sandžak (Raška) region of South-Western Serbia were first to offer services of transporting goods, almost immediately following the cessation of hostilities (Međedović, 2019).

13 Track II diplomacy or "backchannel diplomacy" is the practice of "non-governmental, informal and unofficial contacts and activities between private citizens or groups of individuals" (Diamond \& McDonald, 1991: 1). Arguably the single most successful such initiative is led by yet another NGO, the Council for Inclusive Governance (CIG) with representatives in Belgrade and Pristina. 


\section{European Human}

work with, as it would become evident later, paid little respect to the concept in the first place; on the contrary, by resorting to inflammatory rhetoric and threats, official Belgrade and Pristina "hijacked" the normalization process and contributed to a context not conducive to organizing activities that would be people-centred, as Alkire stipulates (2003: 4).

Although both Serbia and Kosovo* are post-conflict communities, none of our participants (at the time, at least) had to fear for his/her life, or had their livelihood or dignity threatened; rather, they felt "frustrated" with being "stuck" in societies that are stagnating, held hostage by opportunistic and short-sighted political elites. This context was understood to be a critical impediment to human development, which is why many of our participants considered leaving, typically for one of societies in the West. One of BFPE's goals is to, ultimately, tie these and other individuals into a "human infrastructure" that would help complete the process of European integration as well as democratic consolidation of Serbia (and the Western Balkans). Therefore, we did try to support those individuals who excelled in their environments and were curious to meet their peers. In that sense, our activities corresponded to what is considered the "vital core" of human security - the "freedom people have to do and be" (Alkire, 2003: 3). We - along with a significant part of civil society in Serbia - were hoping to shift the focus from "territories" to "people" and their needs, again in line with the contemporary understanding of human security, just as the first proposals on the final settlement of the Kosovo issue started to arise.

\section{BFPE projects and activities}

The Belgrade Fund for Political Excellence (BFPE) joined a number of civil society organizations from Serbia that started developing project proposals with the aim of establishing connections and bringing people from the two societies closer together. In doing so, the organization was greatly aided by the personality of its founder and President, Sonja Licht. Her personal track record takes us 


\section{European Human \\ Journal of Security}

back to the early 1980s, when her engagement was well recognized in both communities, first as an activist within the nascent civil society and then as the first Executive Director (then President) of the Soros Foundation (the Fund for Open Society) in Yugoslavia. As the conflict escalated, she led the Foundation's efforts aimed at providing medicines to internally displaced persons. Throughout the 1990s, she kept open the communication with leaders of Kosovo Albanian political groups who, in their struggle against Milosevic's regime opted for nonviolent resistance. Later on, she supported the Council for Inclusive Governance (CIG) in its track II diplomacy efforts and has insisted on keeping at least one panel in the program of the Belgrade Security Forum that would be exclusively devoted to Belgrade-Pristina relations since the event's inception in 2011. ${ }^{14}$ Finally, from 2012 to 2015, BFPE implemented the project "Regional Academy for Democracy"15, which included 21 politicians from Kosovo* among 150 younger generation politicians from the region of the Western Balkans (aged 40 or under at the time of selection). All this contributed to the organization having an excellent network of contacts, which is a prerequisite to any meaningful engagement with the other side.

This engagement was not difficult in terms of conceptualization as much as implementation. Not from the viewpoint of finding partners: numerous skilled people with open views have worked in civil society in Kosovo* then as now; rather than fear of people's reaction once reading the call to connect with those on the other side. To avoid the most sensitive "legacy" issues, the first attempts were considered in two policy fields deemed less controversial: local development and environmental protection. From 2012 to 2015, BFPE implemented two such projects: "Local Networking

14 The introduction to the 2019 panel, including an overview of previous panels held from 2012-2018, may be found at the next link: http://www.belgradeforum.org/session/plenary-panel-3-belgrade-and-pristina-normalizing-comprehensively/ (Accessed 11 October 2019)

15 For more detailed information see next link: http://radwb.eu/. 


\section{European Human}

for Sustainable Development (LNSD)" and "Promoting Youth Employment through Social Partnerships and Cooperation (YESPC)". The organization's efforts were recognized by the European Union (its Delegation in Serbia), the Kosovo Foundation for Open Society (KFOS), and the Balkan Trust for Democracy (BTD), three donor organizations which supported both projects.

LNSD had three specific aims: "democratic dialogue on (...) sustainable development; building human capacity through raising awareness and knowledge among representatives of local governments ${ }^{16}$, civil society organizations (...) academic and business communities; and to initiate and develop communication and cooperation between decision-makers in local communities in Serbia and Kosovo*". ${ }^{17}$ It engaged 30 participants (15 from each community), who attended four seminars (one in Belgrade, Niš, Peć/Peje and Prizren) and a study visit (to Rijeka, Croatia). Each event followed a similar pattern: introductory lectures were followed by an on-site visit (i.e. in Rijeka, they visited the County Centre for Waste Management in Marišćina, the Viševac waste deposit site and the Sovjak toxic waste deposit site, as well as the Rijeka Commercial Harbour) (Mihailović, 2014). While attending the final event in Prizren, they worked on a number of recommendations (seven in total), which were then compiled into a policy paper by Darinka Radojević on behalf of BFPE and addressed to their respective governments (Radojević, 2014). Furthermore, participants prepared a draft project proposal ("Elements for a Concept of a Regional Project"), which dealt with the issue of wastewater and pollutants near the Ibar river and envisaged cooperation between five municipalities (Raška, Kraljevo, Rožaje, Kosovska Mitrovica and Leposavić). The YESPC project

16 Project was later marketed as the "the first initiative where local self-government representatives from Kosovo and Serbia met and worked together on questions of sustainable development".

17 For more detailed information see next link: https:// en.bfpe.org/programs/local-networking-for-sustainable-development-lnsd/. 


\section{European Human Journal of Security}

that followed "relied on the results" of LNSD; it was only then that BFPE "decided to initiate a project that would tackle another crucial challenge shared by both societies - dramatic youth unemployment rate" (Belgrade Fund for Political Excellence, 2019). Namely, as of 2014, almost 50\% among those aged 15-24 in Serbia were unemployed, while in Kosovo* this rate went as high as $60 \%$. Apart from the long-lasting effects of the global economic crisis and the pre-existing structural weaknesses in education and the labour market, this unemployment rate could also be attributed to "a serious lack of coordination in the employment policy cycle as a key multi-sector policy for economic growth, welfare and social cohesion". ${ }^{18}$ Here, BFPE benefited from the experience gained from previous projects dealing with the issue of youth unemployment (2014) and support to the establishment of the National Qualification Framework in Serbia $(\mathrm{NQFS})^{19}$, long understood as necessary for linking the education and labour market(s) of the country.

The two projects we have described led to the most ambitious P2P project yet. In cooperation with three partners, TransConflict from Belgrade, Democracy for Development (D4D) from Pristina and NGO Aktiv from Kosovska/North Mitrovica, and again, with the support of the EU (administered through its Delegation in Belgrade), BFPE started implementing the project "Changing Minds: Trust through Innovation". The main goal was to contribute to the establishment of stable relations between Serbia and Kosovo* by nurturing professional relationships that go beyond the boundaries set by dayto-day politics (and the struggle for de/legitimization of statehood) and actually enable us to overcome day-to-

18 "Some of the main challenges facing youth in Serbia and Kosovo are: lack of competences required in the labour market due to poor quality of education and training in relation to labour market needs; lower key competences in comparison to EU peers after primary and secondary schooling; lack of access to capital (financial, physical or social); employer discrimination and inadequate job matching" (Belgrade Fund for Political Excellence, 2019).

19 For more detailed information see next link: https://bfpe. org/programs/nqfs/. 
day challenges of life. To that end, cooperation between different groups of professionals was initiated: architects and urban planners; visual artists (particularly those interested in photography as a powerful medium) and writers; IT start-up owners, developers and "digital entrepreneurs" ${ }^{20}$; and women entrepreneurs. ${ }^{21}$

The project partners envisioned a series of activities aimed at breaking down prejudice, building trust and fostering cooperation by utilizing a people-to-people (P2P) and business-to-business (B2B) approach. It was also decided early on to showcase individuals from Kosovo* who have exhibited excellence in certain fields of human activity to public opinion in Serbia. ${ }^{22}$

As of October 2019 (the project concludes on 31 December 2019, with the possibility of an extension), the partners have managed to organize five expert symposiums: the first, intended for architects and urban planners, in September 2017; the second, for photographers, in May 2018; third one, for writers, in March 2019; fourth, bringing together ecologists in May 2019 (all in Belgrade); and the fifth one, experts in the field of active tourism from 1 to 3 October (Tutin).

The problems experienced by citizens in all three

20 As business and society continue to be transformed by digital technology, these new entrepreneurs in Serbia and Kosovo* are setting up businesses, hiring people - who would otherwise leave influencing changes in laws and practices, representing one of the fastest growing exports.

21 The first network of women entrepreneurs was set up by Transconflict and D4D in 2014 through a UK Embassy-backed project. In September 2014, 90 businesswomen met In Pristina and decided to set up the Forum of Businesswomen from Serbia and Kosovo. The most successful, leading businesswomen were asked to take on the role of Ambassadors of Women Entrepreneurship (Empowering female entrepreneurs in Serbia and Kosovo, 2014). 22 In the original project proposal, submitted in June 2016, the activities were planned to take place in both Serbia and Kosovo*. However, the EU decided to change the propositions of the competition so that all activities were to take place in Serbia (proper). This altered the focus a bit and more than likely affected the project's overall reach.

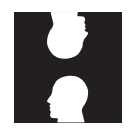




\section{European Human}

Page I 84

cities were the reason why the partners decided to bring architects and urban planners from Pristina, Belgrade and Mitrovica together. The way public spaces are (mis) used, illegal (over)construction, lack of sustainable public transport and communal chaos were easily understood and shared as a common problem in the perception of all participants. The field visits and exchange of opinions that followed were therefore the single most valuable part of the symposiums. ${ }^{23}$ Photographers (from the same three cities) had the opportunity to take part in a master class led by their colleagues active in the Netherlands-based ForHanna Foundation ${ }^{24}$. Following a rigorous selection process, in which aspiring authors had to present their previous work, they attended the master class in Belgrade's Parobrod venue, where Dutch colleagues worked with each of them, showing them ways to improve their work. Next to the master class, there was an exhibition of the work by Dutch photographer Willem Poelstra, whose associates were instrumental in setting up the event. The photographs were accompanied by oral histories of victims of the war in Kosovo, Serb and Albanian alike. ${ }^{25}$ Last but not least, Tutin showed how some of the often overlooked actors, the ones that comprise "traditional" civil society - like mountaineering societies - can be more effective in building lasting bonds and brought together over a concrete project. In the case of this isolated and poor municipality (even by the region's standards), this was building a base (or mountain) camp, followed by an even more ambitious project, a via ferrata for those interested in experiencing alpinism in a safe environment. ${ }^{26}$

23 In Belgrade, architects and urban planners visited the controversial Belgrade Waterfront development, and toured New Belgrade as an example of a planned city.

24 For more detailed information see next link: http://www. forhanna.com/.

25 For more detailed information see next link: http://www. forhanna.com/project/willem-poelstra/. Poelstra, who has since passed away, first held the exhibition "For Hanna, Future Stories from the Past" in Pristina in 2016.

26 One of the most successful projects of this kind is "Via Ferrata Berim", set up by "Outdoor in" organization. One of its founders and key individuals is Dragiša Mijačić, also an expert in 
The partners resorted to another innovative method - hackathons. These events offer an excellent platform for collaboration: IT experts and enthusiasts would come together and work on new applications (or "tools") with a socially conscious "twist" to everyone's benefit. The Hackathon was held at an existing IT hub in Belgrade - Startit - which already serves as a rallying point for the community and a general place of collaboration and inspiration. The focus was more on understanding the context, problem-solving and developing applications than selling the applications in one of the stores available online for a profit. The participants were divided into teams and assisted by a mentor, an experienced IT professional and given 48 hours to come up with a societal problem and a solution. One app, for instance, was meant to help tourists visiting the region for the first time to learn more about the monuments built in former Yugoslavia; another was meant to enable small and medium sized enterprises (SMEs) find their match in a given field. ${ }^{27}$

We have mentioned women entrepreneurs as another all-important target group. The reason for including them was manifold: first, previous experiences have shown that women are pioneers of cooperation, less obsessed with rigid formulations of what is and what is not allowed. Second, because of their less than advantageous position in both societies, they had to work harder to overcome prejudice and build their businesses. Third, they had the potential of inspiring - and perhaps hiring - other women, who would follow in their footsteps. The first

local development and director of civil society organization InTER (Institute for Territorial Economic Development), who used all his experience and networks to build an example of inter-ethnic collaboration; a "peace-building exercise", in his own words. It was upon Mijačić's suggestion that BFPE proposed active tourism as the topic of one of the symposiums to its partners. For more detailed information see next link: http://www.ibarski-kolasin. org/turisticka-ponuda/via-ferrata/298/via-ferrata-berim/.

27 Success of this particular method encouraged BFPE to use it in its other projects. For instance, "Dialogue for the Future", ongoing since March 2019, next to 4 seminars also envisages 2 hackathons (Belgrade Fund for Political Excellence, 2019). 


\section{European Human}

activity within the scope of the project that the partners helped organize was to participate in the Regional Fair of Western Serbia (SPREG 2018) in Valjevo held from 29 to 31 March 2018. Together with their colleagues from the host cities, Šabac and Čačak, guests from Pristina and Mitrovica had the opportunity to present their products and services at one of the stands that had been booked especially for the occasion. The attending businesswomen were owners or directors of micro and small companies restaurants, jewellery and fashion studios, beauty salons, and medium-sized companies in the hospitality and food and beverages industry. Their next visit is planned for 26-29 November 2019, when the "Fair of Ethno Food and Drinks" takes place at the Belgrade Fair.

The project's most ambitious undertaking was bringing successful individuals, who have excelled in a certain field of human activity, to audiences in Belgrade and other major cities. The first such person, who came to Belgrade with the great assistance of colleagues from D4D, was Uta Ibrahimi, the first woman from Kosovo* to climb Mount Everest. More than 40 mountaineering and alpinism enthusiasts came to Belgrade's Centre for Cultural Decontamination (CZKD) to hear her story on 16 November 2017. They listened on as she talked about what happens to the human body at such altitude, how one can mentally and physically prepare him/herself for such an expedition, and what was next in store. Furthermore, the talk was moderated by Goran Ferlan, a well-known Serbian alpinist, marathon runner, and - retired special forces colonel, who also fought in the Kosovo War. Over the course of one evening, therefore, the partners were able to showcase an example of overcoming a difficult past and looking towards the future. ${ }^{28}$

The "Changing Minds" project is supposed to end by 31 December 2019. However, two of its aspects are going to continue. The first concerns the production

28 Reports in Albanian were also published by Kosovo media. For instance, see: Uta Ibrahimi merr pjesë në prezantimin publik në Beograd, 2017. 


\section{European Human}

and broadcasting of a documentary highlighting some of the project's achievements on television stations with regional coverage. Second, four presentations by "exceptional individuals" are yet to take place and BFPE and its partners will seek support from other interested donors in hosting such events.

\section{Objective limits}

87 I Page

The described projects were heavily dependent on a changing political context. At the time of their conceptualization, the process of normalization had just begun. Both sides seemed genuinely committed to attaining European Union membership and thus acted accordingly. It seemed as if there was space and understanding for such activities. However, by late 2016, the relations had started to worsen; there was little or no progress in the technical dialogue, and agreements reached were not either not being implemented or their implementation had been stalled. Of these, the most notable is certainly the agreement on the Association of Serb Municipalities (ASM), protracted since mid-2015. As uncertainty grew, several high profile incidents ensued ("the Train Affair"; the arrests of high level civil servants on both sides or at the border/boundary; incursions to the North from Pristina by special police), ending with the decision of the Kosovo* government to impose 100\% tariffs on Serbian goods as a way of retaliating against Serbia's campaign aimed at revoking recognitions.

The activities were affected due to and by several other factors as well. One of those factors could be described as "pressure from above". The targeted professionals had to be careful and obtain permission from their superiors, who were less likely to grant them at a time of heightened tensions. Many of our participants were, after all, state employees. There was also "peer pressure": not all co-workers approved of the idea to meet and connect, especially if they came from war-affected areas. Stateowned institutions were, as expected, the most difficult to penetrate leading to some unpleasant surprises; for 


\section{European Human \\ Journal of Security}

instance, at one state university, the first meeting seemed promising, but ended in disappointment and without any actual support from the institution.

There was also concern and fear for one's safety, which was understandable, especially in the wake of incidents. At times, the fear (concern) went directly against what was the rational thing to do: for instance, the organization came close to setting up a workshop for microbiologists at the height of the smallpox epidemic in late winter/early spring 2018. Despite obtaining recommendation letters from the very top of decision-making in Serbia, in spite of clear, shared public interest and a secured venue (the infectious disease clinic at the Belgrade Clinical Centre), the participants from Pristina backed out at the very last moment. What typically happens in these situations is that one individual gets "cold feet" and decides against participating - a chain reaction then ensues and the number of confirmations drops from 10 or 15 to 0 . With hindsight, the decision to include medical doctors was, despite best intentions, too ambitious.

Next, the organizers had their own misconceptions about certain target groups. Not all IT experts, for instance, were open for collaboration, despite the positive image of tech-savvy individuals. Not all businessmen or women were interested in attending a fair or a B2B event in a smaller city instead of a major market in places such as Belgrade or Novi Sad. Concern for personal safety (large city vs. small town) was also present. There were situations where locals (experts coming from the host city) were the least represented, while it should have been the other way around, leaving the organizers to explain why this was so.

Time constraints also played a role. Preparations for an event could take months. In the meantime, a better opportunity - a fair, festival or other manifestation would present itself and be missed. On several occasions, the organizers found out about such an event too late. Time constraints were also among the reasons why medical doctors were not an ideal target group. In both 
Serbia and Kosovo*, they are among professionals with the least time available, often working long hours and holding more than one job. For them the only pull factor would have been to have a world-renowned professional who excelled at his/her work deliver a presentation or demonstrate a radical new method, but the project's budget did not allow for this.

\section{Lessons learned}

The partners who implemented the projects described above have learned several important lessons. The first is to think of the target groups' needs in advance. Entrepreneurs will come if there is a way for them to either sell their product or find new suppliers with lower prices. The second is to make sure to have the locals' support. Fairs may be organized by local councils, regional bodies, and other state-owned or affiliated entities; having local businesses present looking to expand to new markets is helpful. The third is to have the budget in mind. The participants may not be ready to invest their own funds into travel and accommodation; covering one part of it helps. Also, mentors and experts are expensive. The fourth is that visibility must be ensured in both Serbia and Kosovo*. The content prepared by the Innovation Center Kosovo (ICK in short, a premier hub for IT professionals in Pristina), broadcast via Facebook ${ }^{29}$ is a perfect example of a group of young people who not only came to learn and find new business opportunities, but also enjoyed the city and met new friends. Most importantly, the partners opted early on for an approach where partnerships with other initiatives that were more "at home" with the proposed activity were actively sought out. In Belgrade, BFPE contacted the Krokodil festival on Transconflict's recommendation; in Pristina, D4D reached out to ICK. This enabled partners to showcase not only people but

29 For more detailed information see Facebook album „ICK to Belgrade", available at: https://www.facebook.com/media/ set/?set=a.2036470319749592\&type=3. 


\section{European Human}

also their efforts and to inspire similar ones to take place.

Where our efforts fell short was "translating into operational policies and projects by principled procedures" (Alkire, 2003: 6). Neither Government of Serbia, or its Office for Kosovo and Metohija have put policies in place that bring professionals together. Given the size of the

Page I 90 challenge ahead - the ethnic distance between Serbs and Albanians remains among the greatest in the region - and the rhetoric employed by political leaders on both sides, the organization's efforts aimed at peacebuilding will continue, albeit in a slightly altered form. 


\section{REFERENCES}

A credible enlargement perspective for and an enhanced EU engagement with the Western Balkans, COM

(2018) 65 final. (2018). Strasbourg: European Commission.

Alkire, S. (2003). A Conceptual Framework for Human Security. Oxford: University of Oxford Centre for Research on Inequality, Human Security and Ethnicity.

Belgrade Fund for Political Excellence. (2019). Dialogue for the future. Available at: https://en.bfpe.org/ programs/dialogue-for-the-future/ (accessed 13 October 2019).

Belgrade Fund for Political Excellence. (2019). Promoting Youth Employment through Social Partnerships and Cooperation (YESPC). Available at: https://en.bfpe. org/programs/promoting-youth-employmentthrough-social-partnerships-and-cooperationyespc/ (accessed 16 June 2019).

Diamond, L., \& McDonald, J. (1991). Multi-track diplomacy: A systems guide and analysis. Grinnell: Iowa Peace Institute.

Empowering female entrepreneurs in Serbia and Kosovo. (2014). Retrieved October 13, 2019, from http:// www.transconflict.com/2014/10/empoweringfemale-entrepreneurs-serbia-kosovo-910/.

Hahn: I put forward free trade ideas before Kosovo* and Serbia. (2018). Retrieved June 15, 2019, from https://europa.rs/hahn-i-put-forward-free-tradeideas-before-kosovo-and-serbia/?lang=en

Janjić, D. (2015). Sprovođenje Briselskog sporazuma i EU integracije Srbije [Implementation of the Brussels Agreement and EU integration of Serbia]. Forum za etničke odnose, 13 February, 2015, Retrieved 
October 9, 2019, from http://fer.org.rs/dr-dusanjanjic-sprovodjenje-briselskog-sporazuma-i-euintegracije-srbije/

Kosovo-Serbia Policy Advocacy Group Consortium. (2019). Technical agreements between Belgrade and Pristina: transport, energy, trade [Public event].

Page I 92 Međedović, N. (2019). Serbian Chamber of Commerce, presentation at the event "Technical agreements between Belgrade and Pristina: energy, trade and regional development", organized by KSPAG, Novi Pazar, 3 October 2019

Mihailović, I. (2014). Representatives of civil society from Serbia and Kosovo* are learning more on sustainable development in Rijeka. BFPE, April 3, 2014, Retrieved October 19, 2019, from https:// en.bfpe.org/representatives-of-civil-societyfrom-serbia-and-kosovo-are-learning-more-onsustainable-development-in-rijeka/

Radojević, D. (2014). Local Networking for Sustainable Development. Belgrade: BFPE.

Srbija bi mogla da izgubi milione evra zbog mera Kosova [Serbia could lose millions of euros because of Kosovo's Measures]. (2018). Retrieved June 15, 2019, from http://www.seebiz.eu/srbija-bi-moglada-izgubi-milione-evra-zbog-mera-kosova/ar185234/

Uta Ibrahimi merr pjesë në prezantimin publik në Beograd [Uta Ibrahim attends a public presentation in Belgrade]. (2017). Retrieved October 13, 2019, from http://www.gazetatribuna.com/arena/utaibrahimi-merr-pjese-ne-prezantimin-publik-nebeograd/.

Vujadinović, D. (2018). CEFTA na Balkanu [CEFTA in the Balkans]. Danas, 17 December, 2018, Retrieved June 15, 2019, from https://www.danas.rs/kolumna/ dragan-vujadinovic/cefta-na-balkanu/ 